\title{
Interference and facilitation effects of primes upon verification processes
}

\author{
JEROME L. MYERS and ROBERT F. LORCH, JR. \\ University of Massachusetts, Amherst, Massachusetts 01003
}

\begin{abstract}
Priming effects on sentence verification were investigated. The semantic relation of the prime and the probe, and the interval between prime and probe presentation (SOA), were varied for both ambiguous and unambiguous sentences. Reaction time to decide that a sentence was true or false was longer if the preceding prime was a word that was unrelated to the probe than if the prime was the word "blank." In contradiction of Posner and Snyder's (1975) claim that conscious processes develop slowly, this result was found at SOAs as short as $250 \mathrm{msec}$. Verification performance was facilitated for both sentence types when the prime word was the first of the to-bepresented probe sentence, but the magnitude of the facilitation effects depended upon the truth value of the probe, the associative strength of the subject and predicate of the probe sentence, and upon SOA. These findings indicate that priming affects the processing of relations among concepts in semantic memory, as well as the encoding of the probe.
\end{abstract}

The processing of an input by our perceptual and memory systems has immediate consequences for succeeding inputs to those information processing systems. The manner in which some initial "priming" stimulus affects a response to a subsequent stimulus depends upon how the successive inputs are related on perceptual and semantic dimensions. Priming effects do not depend solely upon the relation between the long-term representations of the prime and probe stimulus, however. The direction and magnitude of priming effects also depend upon the validity of the prime as a predictor of the probe stimulus and upon the length of the interval between presentation of the prime and presentation of the probe. Under what conditions does a prime facilitate or interfere with retrieval of information from memory? What is the role of the time interval between prime and probe presentation? How do priming effects depend upon the nature of the probe and its relation to the prime? Using a semantic verification task, we have addressed such questions in the experiments reported in this paper.

Most of the previous research on priming has employed a lexical decision task which requires the subject to determine whether a letter string is a word. The interesting result in this task is that subjects detect a word faster when it has been preceded by a semantically related word than when it has been preceded by an unrelated word or by a neutral stimulus (Meyer \& Schvaneveldt, 1971). This facilitation effect has generally

The research reported in this paper was supported by Grant MH-25434-02 from the National Institute of Mental Health to Jerome L. Myers and by a grant of computing time from the University Computing Center at the University of Massachusetts in Amherst. Address reprint requests to Jerome L. Myers, Department of Psychology, University of Massachusetts, Amherst, Massachusetts 01003. been attributed to a spread of activation among concept nodes close to each other in a semantic network (Schvaneveldt \& Meyer, 1973). An important question about priming effects is whether the process initiated by the prime is automatic or whether it requires the subject's conscious attention. Recent evidence suggests that both automatic and conscious processes underlie priming effects.

Posner and Snyder (1975) have defined an automatic process as one that is rapidly developing, inhibitionless, and initiated by a stimulus without (the necessity of) the subject's intention or awareness. In contrast, conscious processes are controlled by a central, limitedcapacity processor and thus are characterized as slowly developing, intention-requiring processes that do interfere with other activities. This distinction between automatic and conscious processes has received its clearest support in a lexical decision study by Neely (1977). Neely varied the interval between presentation of a prime word and a subsequent probe letter string, the semantic relation of the prime and probe words, and the validity with which the prime predicted the nature of the probe word. When the stimulus onset asynchrony (SOA) was only $400 \mathrm{msec}$, priming effects appeared automatic: Time to respond to a probe word was shorter if the prime was semantically related, while there was no effect of the predictive validity of the prime nor was there any interference if the prime and probe word were semantically unrelated. At longer OSAs, priming effects appeared conscious: Reaction time (RT) did not depend upon the semantic relation of the prime and probe, but it was shorter if the probe word was predicted by the prime and longer if the probe was not consistent with expectations set up by the prime.

Neely's results provide strong support for the PosnerSnyder model, but they do so in a limited context. 
The lexical decision task does not require comprehension in any ordinary sense of the word, and thus it places relatively few processing demands upon the subject. A task requiring more semantic processing may produce results different from those predicted by Posner and Snyder and observed by Neely. Specifically, priming interference may develop more rapidly in a semantic task than in less demanding tasks such as lexical decision (Neely, 1977) or letter matching (Posner \& Snyder, 1975). It may be that subjects can allocate limitedcapacity processes very flexibly; thus, perhaps the speed with which conscious processes are involved and the amount of capacity allocated in a task depend importantly upon task difficulty. This suggestion is consistent with a modified definition of automatic and conscious processes that does not include the speed with which the processes develop as a distinguishing characteristic. In fact, Posner (1978) has recently modified his earlier position in just this manner in response to recent findings from secondary probe tasks which indicate that interference effects may, indeed, develop very rapidly after the onset of a stimulus (Comstock, 1973; McLean, reported in Posner, 1978; McLean \& Shulman, 1978).

An alternative theoretical basis for the suggestion that interference effects may develop quite rapidly does not distinguish automatic and conscious processes at all but, instead, proposes that all processing involves a single limited-capacity system (Norman \& Bobrow, 1975). According to this view, processing a prime always requires capacity, but interference with the probe task results only when the capacity that is uncommitted at the time of probe presentation is insufficient to complete probe processing. Thus, when the probe task is relatively undemanding (e.g., lexical decision), interference effects will be small or nonexistent; when the probe task is complex and capacity-demanding (e.g., verification), interference effects will be observed.

Although several studies of priming have been done using semantic tasks, they have not investigated the possibility of interference effects at short SOAs. They either have not involved miscuing (Ashcraft, 1976; Collins \& Quillian, 1970; Homa \& Silver, 1976; Loftus \& Loftus, 1974) or have used only a long SOA (Yates, 1978 ). The primary purpose of the present research is to examine the possibility of rapidly developing priming inhibition by studying performance in a semantic task under conditions in which attention is occasionally misdirected at short SOAs. The subjects' task in our experiment is to verify whether the first word of a pair is a member of the category designated by the second word of the pair. On most trials, the word pair is preceded by a neutral cue (i.e., the word "blank") or by the first word of the to-be-presented pair; on the remaining trials, the cue is neither a word in the subsequent pair nor the word "blank." The subjects' attention is misdirected on some trials in one of two ways: Either (1) the cue is unrelated to either word in the subsequent pair or (2) the cue is a homograph and the subsequent word pair employs the infrequent sense of the homograph. Concerning the latter condition, Yates (1978) found facilitation on such trials at long SOAs; however, he did not investigate short SOAs and his baseline was trials employing an unrelated cue rather than a neutral cue. We employ a neutral cue baseline and include both a short and long SOA. It is possible that the short SOA will permit only the activation of the more frequent sense of the homograph, thus resulting in interference when the infrequent sense appears.

A second purpose of the study is to further investigate facilitation effects due to priming. We have noted that the great majority of priming studies have employed lexical decision tasks, whereas the few studies demonstrating facilitation effects in more complex tasks have employed long SOAs (Ashcraft, 1976; Collins \& Quillian, 1970; Loftus \& Loftus, 1974; Yates, 1978). The present study is designed to extend our understanding of the nature of facilitation effects by including both short and long priming intervals in a semantic task.

\section{METHOD}

\section{Subjects}

Subjects were 24 undergraduate volunteers from psychology courses at the University of Massachusetts. All subjects received course credit for their participation.

\section{Materials}

Four different procedures for item construction corresponded to the four basic item types of the experiment: true and false homographs and nonhomographs.

True nonhomographs. A total of 144 exemplar-category word pairs were selected from two normative sources (Battig \& Montague, 1969; Shapiro \& Palermo, 1970) to serve as true nonhomograph items. Half of the exemplars were frequently given, or high-dominant, instances of the category with which dominant instances of their respective categories (e.g., TurkeyBird). All pairs formed true statements when used to construct a sentence of the form: "An exemplar is a category." The highand low-dominant exemplars were roughly equated for word length (high dominant: $\mathrm{M}=5.48, \mathrm{SD}=1.44$; low dominant: $M=5.55, S D=1.42$ ) and for frequency of usage (high dominant: $\mathrm{M}=27.23, \mathrm{SD}=36.13$; low dominant $: \mathrm{M}=28.98, \mathrm{SD}=49.46$; frequency data from Kučera \& Francis, 1967).

False nonhomographs. After the true nonhomograph items were generated, another 144 exemplars were selected from the norms to serve as false items. Half of the exemplars were high dominant and half were low dominant in their respective categories. These exemplars were paired with the categories from the true word pairs so that the new set of exemplar-category pairs formed false statements when used to construct a sentence of the form: "An exemplar is a category." Each high-dominant exemplar was assigned to a category related to the category from which it was selected (e.g., London-Country); each low-dominant exemplar was paired with an unrelated category (e.g., HornBeverage). The high- and low-dominant exemplars were roughly equated for length (high dominant: $M=5.48, S D=1.51$; low dominant: $M=5.48, S D=1.38$ ) and frequency of usage (high dominant: $\mathrm{M}=54.37, \mathrm{SD}=101.90$; low dominant: $\mathrm{M}=34.63$, $\mathrm{SD}=54.61$; frequency data based on KuXera and Francis, 1967). A complete list of true and false nonhomograph items is presented in Appendix A. 
PRIMING EFFECTS ON VERIFICATION

True homographs. Stimuli for the homograph items were selected from several sources (Cramer, 1970; Geis \& Winograd, 1974; Kausler \& Kollasch, 1970; Schvaneveldt, Meyer, \& Becker, 1976). True homographs were selected subject to two important constraints. First, the two senses of the homograph had to be relatively disparate in frequency of usage, as determined by the relative proportions of free associations to the homographs that were related to its respective senses. Second, it had to be possible to generate a one-word superordinate for the homograph. For each homograph selected, a superordinate noun was generated which formed a true sentence when it was used to complete a sentence of the form: "A homograph is a superordinate." A total of 48 homograph-superordinate word pairs were generated in this manner. For half of the pairs, the superordinate corresponded to the dominant, or frequent, sense of the homograph (e.g., Race-Contest); for half of the pairs, the superordinate corresponded to the infrequent sense of the homograph (e.g., Bridge-Game). A complete list of the true homograph pairs is presented in Appendix B. It should be noted that no data were available concerning the associative frequency of the secondary meaning of three of the infrequent-sense pairs (Pick-Tool, Pit-Seed, Plane-Tool). An attempt was made to select items roughly equated across levels of dominance for: length of the homograph word (frequent sense: $M=4.58$, $\mathrm{SD}=1.28$; infrequent sense: $\mathrm{M}=4.38, \mathrm{SD}=.97)$; frequency of usage of the homograph (frequent: $\mathrm{M}=34.17, \mathrm{SD}=35.82$; infrequent: $M=62.38, S D=51.44)$; length of the category word (frequent: $M=6.33, S D=2.44$; infrequent: $M=5.83$, $\mathrm{SD}=1.97$ ); and frequency of usage of the category word (frequent: $M=57.5, S D=53.28$; inf requent: $M=67.83, S D=70.15$ ).

False homographs. An additional 48 homographs were selected from the norms and paired with a word that was related to one sense of the homograph, but not in a categorical manner (e.g., Rug-Floor, Bark-Tree, Shower-Bride, Mine-Gold). These items were not of theoretical interest; rather, they were used as "fillers" in order to equate the number of true and false word pairs in the experiment and to insure that subjects could not respond to true homograph pairs merely by noting that the first word in the pair was a homograph.

\section{Design}

Although homograph and nonhomograph items were randomly sequenced within each block, the assignment of the two item types to cuing conditions differed. We will therefore treat the two designs separately. A summary of the complete experimental design is presented in Table 1.

Nonhomographs. The basic design for the nonhomograph items involved four variables: truth value, dominance, cue, and SOA. All subjects were tested under all conditions. The truth and dominance manipulations are described below.

There were four cue conditions, although data from the related-cue condition were not analyzed. (1) Each word pair in the neutral-cue condition was preceded by the word "blank." Neutral-cue trials provided a baseline for measuring facilitation and interference effects in the other cuing conditions. (2) In the identical-cue condition; the cue word and the first word (propositional subject) of the subsequent word pair were the same. (3) On unrelated-cue trials, the cue word was a category exemplar that was unrelated to either word in the subsequent pair. High-dominant exemplars cued high-dominant word pairs and low-dominant exemplars were used to cue low-dominant pairs. (4) On related-cue trials, the cue word was related to the category term of the word pair but was not identical to either word in the pair. For true word pairs, the cue was not an exemplar of the category, despite its relatedness to the category (e.g., Clock/Hour-Time, City/Norway-Country); for false word pairs, the cue was an exemplar of the category (e.g., France/ParisCountry, Oil/Pansy-Fuel). These items were included as filler because the relation of the cue to the category word was not a reliable index of the truth value of the word pair; thus, it was
Table 1

Number of Items in Each Cell of the Experimental Design

\begin{tabular}{|c|c|c|c|c|}
\hline \multirow[b]{3}{*}{ Cue } & \multicolumn{4}{|c|}{ SOA } \\
\hline & \multicolumn{2}{|c|}{ Strong Association } & \multicolumn{2}{|c|}{ Weak Association } \\
\hline & Short & Long & Short & Long \\
\hline & \multicolumn{4}{|c|}{ True Homograph } \\
\hline Neutral & 6 & 6 & 6 & 6 \\
\hline \multirow[t]{2}{*}{ Identical } & 6 & 6 & 6 & 6 \\
\hline & \multicolumn{4}{|c|}{ False Homograph } \\
\hline Neutral & 6 & 6 & 6 & 6 \\
\hline \multirow[t]{2}{*}{ Identical } & 6 & 6 & 6 & 6 \\
\hline & \multicolumn{4}{|c|}{ True Nonhomograph } \\
\hline Neutral & 12 & 12 & 12 & 12 \\
\hline Identical & 12 & 12 & 12 & 12 \\
\hline Unrelated & 6 & 6 & 6 & 6 \\
\hline \multirow[t]{2}{*}{ Related } & 6 & 6 & 6 & 6 \\
\hline & \multicolumn{4}{|c|}{ False Nonhomograph } \\
\hline Neutral & 12 & 12 & 12 & 12 \\
\hline Identical & 12 & 12 & 12 & 12 \\
\hline Unrelated & 6 & 6 & 6 & 6 \\
\hline Related & 6 & 6 & 6 & 6 \\
\hline
\end{tabular}

Note-In the case of homographs, "strong" and "weak" associations refer to frequent and infrequent senses, respectively. Although false homographs were separated into frequent and infrequent sense on the basis of intuitive judgments, we have no objective basis for making this assignment.

hoped that subjects would be discouraged from any strategy that involved not reading the exemplar word and basing responses on the cue-category relation. The low error rates $(4 \%)$ found for these items indicate that their inclusion had the desired effect of forcing subjects to read both members of the word pair and respond appropriately.

The assignment of word pairs to the related-cue condition was the same for all subjects. There were 12 word pairs assigned to each of the four combinations of truth and dominance. The critical homograph items presented in Appendix A were randomly assigned to the remaining three cuing conditions, with a new random assignment carried out independently for each subject. The only constraint on each random assignment was that there be 24 neutral-cue items, 24 identical-cue items, and 12 unrelated-cue items in each of the four combinations of truth and dominance.

There were two levels of the fourth within-subject variable of SOA: short $(250 \mathrm{msec})$ and long $(1,250 \mathrm{msec})$. Half of the items at each combination of truth, dominance, and cue were assigned to each SOA; a new random assignment was made for each subject.

Homographs. There were 24 word pairs at each combination of truth and "dominance" (frequency of sense) for the homographs, although there was no objective basis for the assignment of the false pairs to dominance levels. Half of the items at each combination of truth and dominance were randomly assigned to be cued with a neutral cue and the other half were assigned an identical cue. As with the nonhomographs, the assignment was carried out independently for each subject. The items within each combination of dominance, truth, and cue type were then further divided at random for assignment to the two SOAs. Again, a new assignment of items to SOAs was made for each subject.

Homograph and nonhomograph items were randomly and independently assigned to six blocks of 64 items each for each subject, with the constraint that the experimental conditions were uniformly distributed across the six blocks. An additional 
set of 64 word pairs was generated for use in the initial, practice block of the experiment. The characteristics of the practice block were the same as those of the test blocks.

\section{Procedure}

Subjects were tested individually in an experimental session that lasted approximately $1 \mathrm{~h}$. Each subject was seated in front of a video display screen with a hand resting at each of two response levers. On each trial, the subject was presented a warning stimulus consisting of two Xs positioned slightly left and above center on the screen. The warning stimulus served both to alert the subject that the trial was beginning and to mark where the subsequent cue would appear. After a $750-\mathrm{msec}$ interval, the warning stimulus was erased and replaced by the cue. On neutralcue trials, the cue was the word "blank"; on identical-cue trials, the cue was the first noun in the to-be-presented word pair; on unrelated-cue trials, the cue was semantically unrelated to either of the words in the to-be-presented word pair; on related-cue trials, the cue was related to the category word of the word pair. The cue was presented for $250 \mathrm{msec}$, then erased. Finally, after either a short interval $(250 \mathrm{msec})$ or a long interval $(1,250 \mathrm{msec})$ from the onset of the cue, a word pair was presented. The words in a pair were presented one above the other, with the top word appearing directly below where the cue had been presented.

Subjects were instructed to determine for each word pair that was presented whether the top word was an exemplar of the category designated by the bottom word. They were told to do this by inserting the phrase "is a" between the two words and deciding whether the resulting sentence was true or false. They were instructed to pull the right-hand response lever to respond "true" and the left-hand response lever to respond "false." Subjects were also informed that they should use the cue (when it was a word other than "blank") to prepare for the upcoming word pair by trying to think of categories to which the cue word belonged.

When a subject responded to a word pair with a lever pull, the display was erased. If the response was correct, the next trial began automatically after a 2.5 -sec interval; if the response was incorrect, the word "error" was presented and the $2.5 \mathrm{sec}$ interval did not begin until the subject signaled that she wished to continue by pulling either response lever.

Each subject received one practice block and six test blocks of 64 trials each. As had been noted, the assignment of items to cuing conditions, SOAs, and blocks was done randomly and independently for each subject. The sequencing of items within each block was randomized separately for each subject. There was a short break of 1-2 min between each block. A PDP-8/e computer controlled the selection and presentation of stimuli in the experiment.

\section{RESULTS}

Several analyses of variance of both response time and error rate data are presented in this section. The reported statistics are not the quasi-F tests usually performed in related studies. Because items were randomly assigned to cue and SOA conditions independently for each subject, item variability contributed to interactions involving subjects and either of these variables. Thus the proper procedure is to test each effect against its interaction with subjects (Clark, 1973; Myers, 1979). The only exceptions are the main effects of truth and dominance and their interaction, since the item assignments at each combination of these variables was the same for all subjects. The observed effects of these manipulations replicated the findings of several previous investigators using different stimuli, however, so tests of truth and dominance against item variability seemed superfluous. Note that in the tests reported, all Fs are distributed on 1 and 23 degrees of freedom.

\section{Nonhomographs: Neutral and Identical Cue Items}

Response times. Table 2 presents the mean response times and error probabilities for the nonhomograph items. Separate analyses were performed contrasting the neutral-cue items with the identical-cue items and with the unrelated-cue items. Consider the results for the identical-cue items first. Response times were faster for identical-cue items than for neutral-cue items ( $F=$ 121.68 , MSe $=35,328, \mathrm{p}<.001$ ), although the magnitude of the facilitation effect depended upon truth value $(F=5.16, \quad M S e=15,910, p<.05)$. The facilitation effect was larger for false than for true items. Furthermore, considering only the true items, the facilitation effect was larger for low-dominant items at the long SOA than for the other three dominance by SOA combinations; an analysis of variance performed on the true items alone supported this conclusion $(F=4.28$, MSe $=15,982, \mathrm{p}<.05$ ).

Both truth and dominance of the word pair affected response time. Mean response times were faster for true

Table 2

Mean Response Times (in Milliseconds) and Percentage Errors (PE) for Nonhomograph Items

\begin{tabular}{|c|c|c|c|c|c|c|c|c|c|c|c|c|}
\hline \multirow[b]{3}{*}{ Cue } & \multicolumn{6}{|c|}{ True } & \multicolumn{6}{|c|}{ False } \\
\hline & \multicolumn{2}{|c|}{ Short SOA } & \multicolumn{2}{|c|}{ Long SOA } & \multicolumn{2}{|c|}{ Mean } & \multicolumn{2}{|c|}{ Short SOA } & \multicolumn{2}{|c|}{ Long SOA } & \multicolumn{2}{|c|}{ Mean } \\
\hline & Mean & PE & Mean & PE & Mean & PE & Mean & PE & Mean & PE & Mean & $\mathrm{PE}$ \\
\hline & \multicolumn{12}{|c|}{ High Dominance } \\
\hline $\begin{array}{l}\text { Neutral } \\
\text { Identical } \\
\text { Unrelated } \\
\text { Mean }\end{array}$ & $\begin{array}{r}1140 \\
978 \\
1134 \\
1084\end{array}$ & $\begin{array}{l}.992 \\
.997 \\
.979 \\
.989\end{array}$ & $\begin{array}{r}1080 \\
927 \\
1239 \\
1082\end{array}$ & $\begin{array}{l}.982 \\
.993 \\
.969 \\
.981\end{array}$ & $\begin{array}{r}1110 \\
953 \\
1187 \\
1083\end{array}$ & $\begin{array}{l}.987 \\
.995 \\
.974 \\
.985\end{array}$ & $\begin{array}{l}1514 \\
1274 \\
1578 \\
1455\end{array}$ & $\begin{array}{l}.903 \\
.924 \\
.910 \\
.912\end{array}$ & $\begin{array}{l}1489 \\
1244 \\
1578 \\
1437\end{array}$ & $\begin{array}{l}.910 \\
.924 \\
.944 \\
.926\end{array}$ & $\begin{array}{l}1502 \\
1259 \\
1578 \\
1446\end{array}$ & $\begin{array}{l}.907 \\
.924 \\
.927 \\
.919\end{array}$ \\
\hline Mean & \multicolumn{12}{|c|}{ Low Dominance } \\
\hline $\begin{array}{l}\text { Neutral } \\
\text { Identicai } \\
\text { Unrelated } \\
\text { Mean }\end{array}$ & $\begin{array}{l}1382 \\
1246 \\
1449 \\
1359\end{array}$ & $\begin{array}{l}.899 \\
.901 \\
.928 \\
.909\end{array}$ & $\begin{array}{l}1413 \\
1133 \\
1434 \\
1327\end{array}$ & $\begin{array}{l}.902 \\
.898 \\
.912 \\
.904\end{array}$ & $\begin{array}{l}1398 \\
1190 \\
1442 \\
1343\end{array}$ & $\begin{array}{l}.901 \\
.900 \\
.920 \\
.907\end{array}$ & $\begin{array}{l}1399 \\
1164 \\
1486 \\
1350\end{array}$ & $\begin{array}{l}.979 \\
.990 \\
.993 \\
.987\end{array}$ & $\begin{array}{l}1366 \\
1123 \\
1402 \\
1297\end{array}$ & $\begin{array}{l}.990 \\
.986 \\
.979 \\
.985\end{array}$ & $\begin{array}{l}1383 \\
1144 \\
1444 \\
1323\end{array}$ & $\begin{array}{l}.985 \\
.988 \\
.986 \\
.986\end{array}$ \\
\hline
\end{tabular}


than for false items $(F=58.16, \mathrm{MSe}=41,804, \mathrm{p}<.001)$ and were faster for high- than for low-dominant items $(\mathrm{F}=12.59, \quad \mathrm{MSe}=40,030, \mathrm{p}<.005)$. As has been frequently observed in semantic verification studies (e.g., Rips, Shoben, \& Smith, 1973), the two variables interacted $(F=105.95, \mathrm{MSe}=32,659, \mathrm{p}<.001)$ : Subjects responded more quickly to high-dominant true items than to low-dominant true items, while the dominance effect was reversed when the items were false. The only other reliable effect was that average response times were faster at the long SOA than at the short SOA $(F=7.40, M S e=8,257, p<.025)$. Apparently, it is easier to process a word pair when there is more time to prepare following the cue.

Error rates. Only one effect even approached significance in the analysis of error percentages: the Truth by Dominance interaction $(\mathrm{F}=157.91, \mathrm{MSe}=.00400$, $\mathrm{p}<.001)$. The result mimics that observed for response times; subjects made fewer errors on high-dominant true items than on low-dominant true items, but they made more errors on high-dominant false items than on lowdominant false items. Although not reliable, the effects of variables upon error rates were generally in the direction obtained for the response time data. There was no indication of a speed-accuracy tradeoff.

\section{Nonhomographs: Neutral and Unrelated Cue Items}

Response times. When the cue word was unrelated to the subsequent work pair, subjects' responses were slowed relative to the neutral-cue baseline $(F=5.92$, MSe $=180,639, p<.05$ ). As can be seen in Table 2, the magnitude of this interference effect depended upon dominance and SOA; specifically, high-dominant items exhibited more interference than low-dominant items at the long SOA, but less interference at the short SOA $(\mathrm{F}=5.01, \mathrm{MSe}=65,148, \mathrm{p}<.05)$. In order to understand better the nature of this interaction, we analyzed the data for the long and short SOAs separately. At the long SOA, there was a significant interference effect $(\mathrm{F}=4.29, \mathrm{MSe}=173,341, \mathrm{p}<.05)$ and a significant dominance effect $(F=5.43, \mathrm{MSe}=75,931, \mathrm{p}<.05)$, while the interactions involving the cue were not reliable despite considerable variability in the size of the interference effect across combinations of truth and dominance $(p>.05)$. At the short SOA, however, the magnitude of the interference effect depended upon both dominance $(F=5.79, \mathrm{MSe}=46,096, \mathrm{p}<.01)$ and truth and dominance $(\mathrm{F}=10.66, \mathrm{MSe}=52,023, \mathrm{p}<.01)$; these interactions reflect the absence of an interference effect in the high-dominant, true, short-SOA condition coupled with interference effects in the remaining three short-SOA conditions.

As was found for the identical-cue items, responses were faster for true than for false items $(F=91.72$, $\mathrm{MSe}=11,395, \mathrm{p}<.001)$ and for high- than for lowdominant items $(\mathrm{F}=14.53, \mathrm{MSe}=114,646, \mathrm{p}<.01)$. Again, truth and dominance interacted $(F=152.37$,
MSe $=75,899, p<.001)$; response times were faster to high- than to low-dominant true items, while the reverse was found for false items.

Error rates. The Truth by Dominance interaction was also a significant source of variability in the error data $(\mathrm{F}=107.11, \mathrm{MSe}=.0148, \mathrm{p}<.001)$. As in previous analyses, the nature of the interaction was that subjects performed better on high-dominant true items than on low-dominant true items, while the dominance effect was reversed for the false items. This interaction was more pronounced for the neutral-cue items than for the unrelated-cue items $(\mathrm{F}=4.33, \mathrm{MSe}=.0100, \mathrm{p}<.05)$. No other result even approached significance.

\section{True Homographs}

Response times. Table 3 presents mean response times and error probabilities for the true homograph items. Response times were faster to identical-cue items than to neutral-cue items $(F=20.41$, MSe $=$ $72,577, p<.001)$. Although the facilitation effects were larger for high- than for low-dominant items and for the short than for the long SOA, the effects were unreliable $(\mathrm{p}>.05)$. Response times were faster to high- than to low-dominant items $(\mathrm{F}=26.14$, MSe $=$ $37,526, \mathrm{p}<.001)$. As with the nonhomographs, subjects were faster to respond at the longer SOA; this result falls short of conventional significance levels, however $(p=.061)$.

Error rates. Error rates were significantly lower for high-dominant than for low-dominant items $(F=24.03$, MSe $=.02466, p<.001)$ and for neutral- than for identical-cue items $(\mathrm{F}=5.53, \mathrm{MSe}=.01047, \mathrm{p}<.05)$. No other effect approached significance.

\section{DISCUSSION}

The findings in this study fall naturally into three groupings: effects of truth and dominance, identicalcue effects, and unrelated-cue effects. Our finding that response times were faster and errors fewer to highthan to low-dominant true items, while the reverse pattern resulted for false items, is consistent with

Table 3

Mean Response Times (in Milliseconds) and Percentage Errors (PE) for True Homograph Items

\begin{tabular}{|c|c|c|c|c|c|c|}
\hline \multirow[b]{2}{*}{ Cue } & \multicolumn{2}{|c|}{ Short SOA } & \multicolumn{2}{|c|}{ Long SOA } & \multicolumn{2}{|c|}{ Mean } \\
\hline & Mean & $\mathrm{PE}$ & Mean & $\mathrm{PE}$ & Mean & PE \\
\hline & \multicolumn{6}{|c|}{ High Dominance } \\
\hline Neutral & 1503 & .951 & 1430 & .924 & 1467 & .938 \\
\hline Identical & 1316 & .917 & 1205 & .931 & 1261 & .924 \\
\hline \multirow[t]{2}{*}{ Mean } & 1410 & .934 & 1318 & .928 & 1364 & .931 \\
\hline & \multicolumn{6}{|c|}{ Low Dominance } \\
\hline Neutral & 1595 & .882 & 1563 & .812 & 1579 & .847 \\
\hline Identical & 1492 & .819 & 1376 & .764 & 1434 & .792 \\
\hline Mean & 1544 & .851 & 1470 & .788 & 1507 & .819 \\
\hline
\end{tabular}


the findings of several previous investigators (Ashcraft, 1976; Rips et al., 1973; Wilkins, 1971). Since this result is not relevant to the theoretical issues raised in this paper and since its significance has been discussed by previous investigators (e.g., Rips et al., 1973), it will not be discussed further. Rather, we will concentrate on the cuing effects observed.

\section{Effects of the Identical Cue}

The finding that subjects responded faster to a word pair when it was preceded by a cue that was identical to the first word in the pair than when it was preceded by the neutral word "blank" may be explained in several ways. First, and least interesting, facilitation effects would be expected in the identical-cue condition because subjects should save considerable time encoding the first word of the word pair relative to the neutralcue condition. However, subjects were forced to attend to the first word of every pair by the inclusion of related-cue items (e.g., Clock/Hour-Time); that these items were successful in their purpose is demonstrated by the low error rate (4\%) observed for them. Further, although some encoding savings can still be expected in the identical-cue condition, the observed facilitation effects are not solely attributable to effects at encoding. If they were, the magnitude of the facilitation effects would not depend, as they do, upon the truth and dominance of the word pair.

A second possible reason for facilitation effects is that the identical cue may have speeded the encoding of the second word in the probe pair. It is just such encoding facilitation that underlies priming by a semantically related cue in the lexical decision task (Becker \& Killion, 1977; Meyer, Schvaneveldt, \& Ruddy, 1975). Although such an explanation can account for facilitation effects in previous verification experiments (Ashcraft, 1976; Collins \& Quillian, 1970), it is at best a partial account of the present data. This hypothesis predicts more facilitation for high-dominant than for low-dominant pairs because the second word in the word pair is more strongly associated with the cue in the case of the high-dominant items. The results for the nonhomograph items are contrary to this prediction. First, more facilitation was obtained with low-than with high-dominant true items at the long SOA. Second, facilitation effects were larger for false than for true items, despite the fact that even high-dominant false associations (e.g., "A shark is a bird") are weak relative to true associations.

While there must be some savings in the time required to read a word pair in the identical-cue condition, the effects of the identical cue are at least partially attributable to the facilitation of postencoding processes. Consider the pattern of effects observed for the nonhomograph items. The identical cue can facilitate the retrieval of information relevant to the evaluation of the word pair in two ways. First, the identical cue provides a head start on the activation of associates of the subject word of the subsequent probe pair (Anderson, 1976; Collins \& Loftus, 1975). Thus more information about the subject word will be available at the time of probe presentation in the identical-than in the neutral-cue condition. Second, at the long SOA, subjects may actually have sufficient time to activate and attend to the category of the cue before the probe is presented, with a resulting additional savings in retrieval time. For example, given sufficient time, the subject may become aware that jade is a gem or that a stool is a piece of furniture; thus the generated category may be quickly compared with the category term when the word pair is presented. This second source of savings of retrieval time should be greater for low-dominant than for high-dominant items because the relevant category association is much less accessible for the low-dominant items, as indicated by the effect of dominance on response times. This explains why facilitation effects for true nonhomographs increased from the short to the long SOA for the low-dominant items but not for the high-dominant items. A similar trend was observed for the true homographs, but the result was not reliable. This interpretation of facilita. tion effects for true items has at least one testable consequence: The greater facilitation observed for the low-dominant items at the long SOA should be reduced or eliminated if subjects are required to verify several types of relations, as opposed to just categorical relations. Under such conditions, the subject would be less certain about what information to prepare during the interval between cue and probe presentation.

According to the preceding argument, it might be expected that the facilitation effects for the false nonhomographs would also depend upon dominance and SOA. The magnitudes of the facilitation effects were very similar across the four combinations of dominance and SOA, however. This result can be explained if it is assumed that subjects were not responding "false" on the basis of the retrieval of one piece of contradictory information (e.g., in the identical-cue condition, the generation of a category associate which did not correspond to the category term in the probe pair); rather, they responded "false" only after the retrieval of several negative pieces of information or only after the failure to retrieve a confirming association within some search limit. (In other words, while positive responses were based upon a self-terminating search process, negative responses may have been based upon an exhaustive search process.) According to this account, the facilitation effects observed for false nonhomographs were due to encoding facilitation and to the head start on the activation process provided by the identical cue. It is not clear, then, why the facilitation effects observed for the false nonhomographs were larger than those found for the true nonhomographs. Perhaps the greater facilitation effects for the false items reflects a shift in response criterion: On identical-cue trials, subjects allowed less time from the onset of the word pair to 
reach a negative decision because they recognized that, if the exemplar was a member of the probe category, the head start provided by the cue made that information available relatively early. This proposal is consistent with the suggestion that a false response is based upon a failure to retrieve information which confirms that the sentence is true.

The data for the homograph items are rather inconclusive. As has been noted, the facilitation effect observed for homographs did not vary significantly with dominance or SOA, although there was a tendency for facilitation to be greater for items involving the frequent sense than for items involving the infrequent sense of the homograph. Using only a long SOA $(1,500 \mathrm{msec})$, Yates (1978) observed significantly greater facilitation for the frequent or high-dominant sense of a homograph than for the infrequent or low-dominant sense. Yates interpreted his finding as evidence that the retrieval of the infrequent sense of the identical homograph cue interfered with the retrieval of the infrequent sense. It is difficult to interpret the smaller facilitation effects for low-dominant items observed in our study: They may reflect interference with the activation of the less frequent sense of the homograph, or, as the significance tests suggest, no real difference may exist in the rate of activation of the two senses of the homograph.

The interpretation of the homograph data is further complicated by the finding that response times were faster to identical-cue items than to neutral-cue items and at long SOAs than at short SOAs, but there were more errors to identical-cue items and at long SOAs. This speed-accuracy tradeoff did not occur with nonhomograph items, which constituted $75 \%$ of all items in the study. One explanation for the tradeoff may be that subjects respond faster to all probes following the identical cue and following the longer SOA; the identical cue gives a head start to processing of the propositional subject and the long SOA permits the subject to become physically ready to make some response. When the items are relatively easy nonhomographs, the fast responses can be made quite accurately. When the items are homographs, however, a fast response may allow too little time to process the infrequent sense of homographs, thus resulting in errors. This explanation predicts that the accuracy advantage of the short SOA and of the identical cue should be greater for low-than for highdominant items; this was the case, although the result was not statistically significant.

\section{Effects of Unrelated Cues}

Posner and Snyder (1975) proposed that automatic and conscious processes are distinguished with respect to: (1) whether they require capacity (i.e., interfere with other processes), (2) whether they operate under the subject's intentions and with the subject's awareness, and (3) the speed with which the process develops. This distinction between automatic and conscious processes has found its strongest support in Neely's (1977) lexical decision data. As the Posner-Snyder model predicted, the predictive validity of the prime was the crucial determinant of performance at long SOAs, while the semantic relation of the prime and probe was the determinant of performance at short SOAs. Further, an invalid cue resulted in interference at long SOAs, but an unrelated cue did not produce interference at the shortest SOA ( $400 \mathrm{msec})$. Using a semantic verification task, we have also obtained interference due to miscuing at long SOAs. In contrast with the Posner-Snyder model and Neely's data, however, our unrelated cues resulted in interference effects at an SOA of only $250 \mathrm{msec}$. Antos (1979) also recently observed interference effects at SOAs as brief as $200 \mathrm{msec}$ in a lexical decision priming task. These results require revision of Posner and Snyder's (1975) distinctions between automatic and conscious processes.

One approach is to delete the claim that conscious processes are necessarily slowly developing. Posner (1978) recently amended the original theory in just this way. The impetus to the modification came from studies using a secondary probe procedure in a letter-matching task. These studies demonstrate that interference effects may develop quite rapidly after the onset of the first of two successively presented letters that are to be matched (Comstock, 1973; McLean, reported in Posner, 1978; McLean \& Shulman, 1978). According to this proposal, automatic and conscious processes are distinguished only by whether or not they require capacity, awareness, and intention.

An alternative to the preceding modification is to deny the existence of unlimited capacity processes (Norman \& Bobrow, 1975). This proposal effectively denies the automatic-conscious distinction in Posner's point of view because Posner implicitly defines an automatic process as an inhibitionless process and a conscious process as a capacity-limited process. The advantage of this suggestion is that it shifts the theoretical emphasis from the issue of whether a process is or is not automatic (i.e., does it produce inhibition?) to questions concerning the flexibility with which processing capacity can be allocated. At what points in a task are capacity demands the greatest? At what points are they the least? What kinds of task variables alter the way in which capacity is distributed? What are the limits on how quickly capacity can be reallocated?

With respect to the precise pattern of interference effects observed at the short SOA in the present study, the major issue is why the high-dominant true nonhomographs exhibited no interference while interference effects of from 64 to $89 \mathrm{msec}$ were observed for the other three dominance by truth conditions. One way to understand this result is to note that the highdominant true items represent more strongly associated word pairs than the items in the other three dominance by truth cells. Recognizing this, the issue becomes why 
only the most strongly associated items showed no interference at the short SOA. The answer appears to involve the rate at which activation of associates of the two words in the probe pair occurs relative to the rate at which associates of the unrelated cue are activated from the single cue word. The high-dominant true word pairs are sufficiently strongly associated that information relevant to the evaluation of these word pairs is activated before associates of the cue are activated enough to interfere with the evaluation process; this is despite the $250-\mathrm{msec}$ head start given to the cue word. On the other hand, the additional 200 to $400 \mathrm{msec}$ that it takes to evaluate the low-dominant true items and the false items represents enough of a delay that associates of the cue word have been activated sufficiently to interfere with the processing of these items.

\section{CONCLUSIONS}

In summary, two important conclusions are indicated by the data reported here. First, we observed facilitation effects of a prime that could not be attributed solely to effects on encoding processes. Working from a network theory framework (Anderson, 1976; Collins \& Loftus, 1975), we suggested that an identical prime facilitates the retrieval of information relevant to the evaluation of a word pair primarily by providing a head start on the process of activating such information. Second, we observed that presentation of an unrelated cue interfered with the processing of a subsequent word pair at an interval as brief as $250 \mathrm{msec}$. This result led us to reassess Posner and Snyder's distinctions between automatic and conscious processes.

\section{REFERENCES}

Anderson, J. R. Language, memory and thought. New York: Erlbaum, 1976.

Antos, S. J. Processing facilitation in a lexical decision task. Journal of Experimental Psychology: Human Perception and Performance, 1979, 5, 527-545.

Ashcraft, M. H. Priming and property dominance effects in semantic memory. Memory \& Cognition, 1976, 4, 490-500.

Battic, W. F. \& Montague, W. E. Category norms for verbal items in 56 categories: A replication and extension of the Connecticut category norms. Journal of Experimental Psychology Monograph, 1969, 80(3, Pt. 2).

Becker, C. A., \& Killion, J. H. Interaction of visual and cognitive effects in word recognition. Journal of Experimental Psychology: Human Perception and Performance, 1977, 3, 389-401.

ClaRK, H. H. The language-as-fixed-effect fallacy: A critique of language statistics in psychological research. Journal of Verbal Learning and Verbal Behavior, 1973, 12, 335-359.

Coltins, A. M., \& Loftus, E. F. A spreading activation theory of semantic processing. Psychological Review, 1975, 82, 407-428.

Collins, A. M., \& Quillian, M. R. Facilitating retrieval from semantic memory: The effect of repeating part of an inference. In A. F. Sanders (Ed.), Attention and performance III. London: North-Holland, 1970.

Comstock, E. M. Processing capacity in a letter-matching task. Journal of Experimental Psychology, 1973, 100, 63-72.

Cramer, P. A study of homographs. In L. Postman \& G. Keppel (Eds.), Norms of word association. New York: Academic Press, 1970.

Geis, M. F., \& Winograd, E. Norms of semantic encoding variability for fifty homographs. Bulletin of the Psychonomic Society, 1974, 3, 429-431.

Homa, D., \& Silver, R. Triadic decision making in lexical memory. Memory \& Cognition, 1976, 4, 532-540.

Kausler, D. H., \& Kollasch, S. F. Word associations to homographs. Journal of Verbal Learning and Verbal Behavior, $1970,9,444-449$.

Kučera, H., \& Francis, W. N. Computational analysis of present-day American English. Providence, R.I: Brown University Press, 1967.

Loftus, G. R., \& Loftus, E. F. The influence of one memory retrieval on a subsequent memory retrieval. Memory \& Cognition, 1974, 2, 467-471

Mclean, J. P., \& Shulman, G. L. On the construction and maintenance of expectancies. Quarterly Journal of Experimental Psychology, 1978, 30, 441-454.

Meyer, D. E., Schvaneveldt, R. W. Facilitation in recognizing pairs of words. Journal of Experimental Psychology, 1971, 90, 227-234.

Meyen, D. E., Schvaneveldt, R. W., \& Ruddy, M. G. Loci of contextual effects on visual word recognition. In P. M. A. Rabbitt \& S. Dornic (Eds.), Attention and performance $V$. New York: Academic Press, 1975.

Myers, J. L. Fundamentals of experimental design. Boston: Allyn and Bacon, 1979.

NeELY, J. H. Semantic priming and retrieval from lexical memory: Roles of inhibitionless spreading activation and limited-capacity attention. Journal of Experimental Psychology: General, 1977, 106, 226-254.

Norman, D. A., \& Bobrow, D. G. On data-limited and resourcelimited processes. Cognitive Psychology, 1975, 7, 44-64.

Posner, M. I. Chronometric explorations of mind. Hillsdale, N.J: Erlbaum, 1978.

Posner, M. I., \& Snyder, C. R. R. Facilitation and inhibition in the processing of signals. In P. M. S. Rabbitt \& S. Dornic (Eds.), Attention and performance $V$. New York: Academic Press, 1975.

Rips, L. J., Shoben, E. J., \& Smith, E. E. Semantic distance and the verification of semantic relations. Journal of Verbal Learning and Verbal Behavior, 1973, 12, 1-20.

Schvaneveldt, R. W., \& Meyer, D. E. Retrieval and comparison processes in semantic memory. In S. Kornblum (Ed.), Attention and performance IV. New York: Academic Press, 1973.

Schvaneveldt, R. W., Meyer, D. E., \& Becker, C. A. Lexical ambiguity, semantic context, and visual word recognition. Journal of Experimental Psychology: Human Perception and Performance, 1976, 2, 243-256.

Shapiro, S. I., \& Pale rmo, D. S. Conceptual organization and class membership: Normative data for representatives of 100 categories. Psychological Monographs Supplements, 1970, 3(11, Whole No. 43).

Wilkins, A. J. Conjoint frequency, category size, and categorization time. Journal of Verbal Learning and Verbal Behavior, $1971,10,382-385$.

YATES, J. Priming dominant and unusual senses of ambiguous words. Memory \& Cognition, 1978, 6, 636-643. 
Appendix A

List of True and False Nonhomograph Pairs

\begin{tabular}{|c|c|c|c|c|}
\hline \multicolumn{2}{|c|}{ True Exemplars } & \multicolumn{2}{|c|}{ False Exemplars } & \multirow[b]{2}{*}{ Category } \\
\hline High Dominant & Low Dominant & High Dominant & Low Dominant & \\
\hline Swimming & Singing & Fear & Fig & Activity \\
\hline Tiger & Rabbit & Mayor & Soup & Animal \\
\hline Coke & Cocoa & Banana & Mortar & Beverage \\
\hline Tea & Juice & Plum & Horn & Beverage \\
\hline Robin & Turkey & Shark & Teaspoon & Bird \\
\hline Sparrow & Chicken & Herring & Scarf & Bird \\
\hline Chicago & Atlanta & Texas & Sugar & City \\
\hline Rayon & Denim & Shoes & Erie & Cloth \\
\hline Shirt & Shorts & Linen & Dickens & Clothing \\
\hline Socks & Suit & Silk & Cuba & Clothing \\
\hline Green & Gray & Vanilla & Talking & Color \\
\hline England & Ireland & London & Pity & Country \\
\hline Rape & Fraud & Anger & Ellen & Crime \\
\hline Waltz & Ballet & Piano & Marigold & Dance \\
\hline Meter & Micion & Quart & Burlap & Distance \\
\hline Oxygen & Argon & Brick & Swing & Element \\
\hline Hate & Rage & Dancing & Brooch & Emotion \\
\hline Running & Walking & Reading & Artist & Exercise \\
\hline Trout & Guppy & Lion & Banjo & Fish \\
\hline Tulip & Lilac & Oak & Island & Flower \\
\hline Peach & Lime & Orchid & Dormitory & Fruit \\
\hline Coal & Steam & Whiskey & Boots & Fuel \\
\hline Sofa & Stool & Wall & Whip & Furniture \\
\hline Emerald & Amethyst & Necklace & Sleeping & Gem \\
\hline Ruby & Jade & Earring & Snail & Gem \\
\hline Einstein & Edison & Nixon & Melon & Genius \\
\hline Flute & Fiddle & $\mathrm{J} a z z$ & Raspberry & Instrument \\
\hline Violin & Viola & Folk & Wing & Instrument \\
\hline Bracelet & Cufflink & Dress & Lemon & Jewelry \\
\hline Grape & Prune & Soda & Blues & Iuice \\
\hline Spanish & Swedish & Canada & Vest & Language \\
\hline Gin & Brandy & Tomato & Wolf & Liquor \\
\hline Pork & Deer & Salt & Charm & Meat \\
\hline Copper & Carbon & Balsam & October & Metal \\
\hline Dimes & Coins & Pearls & Eating & Money \\
\hline Classical & Concert & Verb & Candy & Music \\
\hline Atlantic & Antarctic & Huron & Stalin & Ocean \\
\hline Senator & Sheriff & Teacher & Sherry & Office \\
\hline Venus & Neptune & January & Gopher & Planet \\
\hline Frost & Burns & Newton & Spruce & Poet \\
\hline Sister & Son & Faulkner & Scote & Relative \\
\hline Aunt & Wife & Mary & History & Relative \\
\hline Mouse & Shrew & Alligator & Utah & Rodent \\
\hline Queen & Earl & Hitler & Driving & Royalty \\
\hline Biology & Geology & Study & Oven & Science \\
\hline Shrimp & Tuna & Rat & Velvet & Seafood \\
\hline Summer & Autumn & Year & Ore & Season \\
\hline Pepper & Ginger & Jello & Plug & Seasoning \\
\hline Triangle & Trapezoid & Watts & Frog & Shape \\
\hline Cobra & Viper & Lizard & Happy & Snake \\
\hline Tennis & Boxing & Sewing & Darwin & Sport \\
\hline Football & Hunting & Writing & Chemist & Sport \\
\hline Doll & Cards & Bomb & Cedar & Toy \\
\hline Maple & Willow & Carnation & Vowel & Tree \\
\hline Elm & Fir & Hill & Crystal & Tree \\
\hline Spoon & Cup & Trumpet & Kennedy & Utensil \\
\hline Bus & Jet & Apartment & Clam & Vehicle \\
\hline Knife & Chain & Spatula & Poppy & Weapon \\
\hline Pine & Teak & Tin & Berlin & Wood \\
\hline
\end{tabular}


Appendix B

List of True Homograph Pairs

\begin{tabular}{llll}
\hline Frequent Sense & Infrequent Sense & Frequent Sense & Infrequent Sense \\
\hline Bank-Institution & Arms-Weapons & Mole-Rodent & Mass-Service \\
Bowl-Dish & Ball-Dance & Mug-Cup & Pen-Enclosure \\
Box-Container & Bat-Animal & Organ-Instrument & Perch-Fish \\
Cabinet-Furniture & Bridge-Game & Poker-Game & Pick-Tool \\
Calf-Animal & Club-Weapon & Pound-Weight & Pit-Seed \\
Contract-Agreement & Count-Nobleman & Pupil-Student & Plane-Tool \\
Corn-Vegetable & Date-Fruit & Race-Contest & Port-Wine \\
Duck-Bird & Deed-Document & Sage-Herb & Punch-Drink \\
Jam-Food & File-Tool & Spring-Season & Rattle-Noise \\
Lie-Fib & Fine-Punishment & Temple-Building & Ring-Sound \\
Maroon-Color & Foot-Measure & Toll-Fee & Sole-Fish \\
Mint-Flavor & March-Month & Watch-Timepiece & Capsule-Spacecraft \\
\hline
\end{tabular}

(Received for publication July 2, 1979; revision accepted April 3, 1980.) 